\title{
Nitric oxide release and distribution following oral and intraperitoneal administration of nitroaspirin (NCX 4016) in the rat
}

\author{
Marina Carini $^{\mathrm{a}, *}$, Giancarlo Aldini ${ }^{\mathrm{a}}$, Marica Orioli ${ }^{\mathrm{a}}$, Angela Piccoli ${ }^{\mathrm{a}}$, \\ Giuseppe Rossoni $^{\mathrm{b}}$, Roberto Maffei Facino ${ }^{\mathrm{a}}$ \\ ${ }^{a}$ Istituto Chimico Farmaceutico Tossicologico, University of Milan, Viale Abruzzi 42, 20131 Milan, Italy \\ ${ }^{\mathrm{b}}$ Dipartimento di Scienze Farmacologiche, University of Milan, Via Balzaretti 9, 20133 Milan, Italy
}

Received 14 July 2003; accepted 21 November 2003

\begin{abstract}
The metabolic fate of nitric oxide (NO) released from nitroaspirin, benzoic acid, 2-(acetyloxy)-3[(nitrooxy)methyl]phenyl ester (NCX 4016), the lead compound of a new class of NO-releasing non steroidal anti-inflammatory drugs (NO-NSAIDs), has been studied in the rat following p.o. and i.p. administration of 100 $\mathrm{mg} / \mathrm{kg}$, by monitoring in plasma the bioactive storage forms of NO (S-nitrosothiols, RS-NO) and its oxidation products (nitrites/nitrates, NOx) by a chemiluminescent assay. In parallel, plasma was analyzed for unchanged drug and metabolites by reverse-phase HPLC. In orally treated rats, no unchanged drug is observed in the 0-24 $\mathrm{h}$ interval post-dosing, but only salicylic acid (SA), NOx and RS-NO. The time-course of SA formation parallels that of plasma NOx (plateau after $6 \mathrm{~h}$ ). Nitrosothiols in plasma are detectable at $1 \mathrm{~h}$, peak at $4 \mathrm{~h}$ postadministration, and decline thereafter. The results relative to i.p. administration show a more pronounced and rapid NO delivery (peak of both NOx and RS-NO at $1 \mathrm{~h}$ and plateau between 1 and $2 \mathrm{~h}$ ), still coincident with the peak of SA, and the presence in plasma of NCX 4015 (a metabolite of NCX 4016 which still bears the nitrate function). In myocardial tissue from p.o. treated rats, no drug or metabolites were ever detected, and the NOx levels were always in the range of the controls. Conversely, following i.p. treatment, we observed a rapid compartmentalization within the heart of the unchanged drug, which rapidly disappears in favour of its breakdown products NCX 4015 and SA, with a concomitant rise in myocardial NOx levels up to $2 \mathrm{~h}$. To check the stability of NCX 4016 in the acidic gastric milieu and to explain the different distribution of the drug following p.o. or i.p. administration, the gastric content of the orally-treated animals at different post-dosing
\end{abstract}

* Corresponding author. Tel.: +39-2-50317532; fax: +39-2-50317565.

E-mail address: marina.carini@unimi.it (M. Carini). 
times was analysed by HPLC. The unchanged drug was detected up to $8 \mathrm{~h}$ post-dosing (levels slowly decreased with time), and the only metabolite to be detected was the O-deacetylated derivative (NCX 4023), which was present in low concentrations up to $4 \mathrm{~h}$ post-dosing. This indicates that NCX 4016 does not undergo biotransformation in the upper part of gastrointestinal tract (no direct release of NO in this district) and that the stomach acts as a reservoir for the drug.

(C) 2004 Elsevier Inc. All rights reserved.

Keywords: NCX 4016 (nitroaspirin); Drug metabolites; NO metabolites (NOx and S-nitrosothiols); Plasma; Heart

\section{Introduction}

Nitroaspirin, benzoic acid, 2-(acetyloxy)-3-[(nitrooxy)methyl]phenyl ester (NCX 4016), is the lead of a new class of anti-inflammatory/antithrombotic agents (Del Soldato et al., 1999) that has been recently proposed by Napoli and Ignarro (2003) and Wallace et al. (2002) as a safer alternative to aspirin for use in hypertensive patients for the primary prevention of cardiovascular diseases. The therapeutic goal of NCX 4016 is to achieve lower gastrointestinal toxicity in comparison to aspirin beside maintaining the anti-inflammatory action. In addition, nitroaspirin has been shown in preclinical studies to be a promising novel agent for colon cancer prevention and treatment (Bak et al., 1998; Rigas et al., 2003; Rigas and Williams, 2002). Both the aspirin and NO moieties of this compound contribute to its effectiveness. The NO moiety exerts its effect through both cGMP-dependent (inhibition of platelet aggregation, vasodilation, inhibition of leukocyte adhesion to the vascular endothelium) and -independent mechanisms (inhibition of inflammatory cytokine synthesis, inhibition of cell proliferation and apoptosis). For this reason the knowledge of the rate of NO release from this novel NO-donor drug is a pivotally crucial first step in determining the time course and spectrum of its pharmacological activity.

In previous studies we have obtained unequivocal evidence that NCX 4016, when incubated with rat blood or when acutely administered by i.p. or oral route in the same animal is able to release NO (Carini et al., 2001). This has been clearly demonstrated by Electron Spin Resonance (ESR) spectroscopy determining NO in radical form as nitrosylhemoglobin $\mathrm{HbFe}(\mathrm{II}) \mathrm{NO}$ and this analytical evidence has provided strong support that the reduced gastrolesivity of the drug in the animal and the other pharmacological effects are due to the release of this important vasorelaxing mediator.

As well as being an unequivocal marker of $\mathrm{NO}$ release, $\mathrm{HbFe}(\mathrm{II}) \mathrm{NO}$ also represents a form of delivery of NO in the blood. In particular, according to the recent theory of modulation of NO bioavailability by erythrocytes (Pawloski et al., 2001; Gow et al., 1999), NO enters the RBC and preferentially binds to the free heme to form $\mathrm{HbFe}(\mathrm{II}) \mathrm{NO}$. This last then transfers NO to $\beta-93-\mathrm{Cys}$ to form S-nitroso-Hb. Bioactive $\mathrm{NO}$ is then exported out of RBCs through the anion exchange protein, band 3 (or AE1), to redox-active thiols which are abundant in plasma and can incorporate $\mathrm{NO}$ and transport it in the circulation in the form of bioactive S-nitrosothiols (RS-NO).

Based on this recent proposed mechanism, as well as being a paracrin mediator, NO can also be considered an endocrine vasoregulator (at least at pharmacological doses) that is able to act distal to the site of its formation through the presence of species in blood that are capable of delivering NO, such as S-nitrosothiols, iron-nitrosyl complexes and nitrites (Gladwin et al., 2003). Since the growing 
evidences of the biological activities of the storage forms of NO and of their therapeutic opportunities (Miller et al., 2003; Alencar et al., 2003; Rassaf et al., 2002), the first aim of this work was to gain a deeper insight into the metabolic fate of NO released from NCX 4016 following p.o. and i.p. administration, by monitoring the plasma levels of the bioactive storage forms of S-nitrosothiols and of nitrites/nitrates (NOx) and to correlate their kinetics of formation with those of plasma levels of the drug and its metabolites. NCX 4016 requires in fact enzymatic denitration to liberate NO (Napoli and Ignarro, 2003) and, as previously demonstrated in in vitro studies in rat liver, the molecule undergoes rapid metabolization of the ester linkage to salicylic acid (SA) and benzenemethanol,3-hydroxy- $\alpha$ nitrate (NCX 4015), the spacer still bearing the nitrate ester, the function more resistant to reductive hydrolysis (Carini et al., 2002).

In the second part of this study we have analysed (HPLC) along the entire post-dosing time, the gastric content of rats p.o. treated with $100 \mathrm{mg} / \mathrm{kg}$. This was done in order to exclude production of $\mathrm{NO} /$ nitrosating species locally in the stomach with potential risk of toxicity, and to determine the kinetics of release from the stomach of NCX 4016 and metabolites.

\section{Materials and methods}

\section{Chemicals}

HPLC-grade and analytical-grade organic solvents were purchased from Merck (Bracco, Milan, Italy). HPLC-grade water was prepared with a Milli-Q water purification system. Benzoic acid, 2(acetyloxy)-3-[(nitrooxy)methyl]phenyl ester (NO-ASA; NCX 4016) and the NO-ASA metabolites: benzoic acid, 2-(hydroxy)-3-[(nitrooxy)methyl]phenyl ester (NCX 4023), benzoic acid, 2-(acetyloxy)-3(hydroxymethyl)phenyl ester (NCX 4017), benzoic acid, 2-(hydroxy)-3-(hydroxymethyl)phenyl ester (NCX 4019) and benzenemethanol,3-hydroxy- $\alpha$-nitrate (NCX 4015) were kindly provided by NICOX S.A. (Sophia Antipolis, France); benzenemethanol, 3-hydroxy (HBA), benzoic acid, 3-hydroxy (HBAC), acetylsalicylic acid (ASA), salicylic acid (SA), ortho-phosphoric acid (85\% w/v), sodium fluoride and N-ethylmaleimide (NEM) were purchased from Fluka Chimica (Milan, Italy). Polyethylene glycol (PEG 400; average molecular weight, 400), potassium iodide, vanadium (III) chloride, sulfanilamide (p-aminobenzenesulfonamide), copper (II) sulphate, ethylene-diaminetetraacetic acid, perchloric acid, glacial acetic acid and $\beta$-glucuronidase $(4.5 \mathrm{U} / \mathrm{ml}) /$ arylsuphatase $(14 \mathrm{U} / \mathrm{ml})$ were purchased from Sigma (Sigma-Aldrich S.r.l., Milan, Italy); S-nitrosoglutathione (GSNO) was purchased from Cayman Chemical (Cabru s.a.s. Milan, Italy).

\section{Apparatus}

LC analyses were carried out on a Hewlett Packard HP 1050 system equipped with a quaternary pump, an UV/VIS diode array detector, an autosampler and a vacuum degasser. Separations were done by reverse phase elution (Merck Licrosphere RP8 column; $250 \times 4.6 \mathrm{~mm}$ i.d.; particle size $5 \mu \mathrm{m}$ ) in the conditions previously described by us (Carini et al., 2002).

Chemiluminescence analyses of plasma NOx and S-nitrosothiols were performed with a Sievers Instruments Model 280 Nitric Oxide Analyzer (NOA ${ }^{\mathrm{TM}}$; Sievers, Boulder, CO, USA; Sensor Medics, Milan, Italy). 


\section{Animal treatment}

Male Wistar rats (Charles River, Calco, LC, Italy; $220 \pm 10 \mathrm{~g}$ body weight) were maintained in compliance with the policy on animal care expressed in the National Research Council guidelines (NRC 1985). The animals were housed individually in stainless steel cages under standard conditions (temperature $22 \pm 2{ }^{\circ} \mathrm{C} ; 50 \pm 10 \%$ relative humidity; artificial light from 06:00 to 20:00 h). Food laboratory chow and drinking water were available ad libitum; animals were fasted overnight before the drug treatment. NCX 4016 was dissolved in PEG $400(150 \mathrm{mg} / \mathrm{ml})$ immediately before administration. In a first set of experiments, rats $(n=5$ for each time point) were orally treated (by gavage) with the drug $(100 \mathrm{mg} / \mathrm{kg})$ and sacrificed $0.5,1,2,4,6,8,12,18,24 \mathrm{~h}$ post-administration. A second group of animals ( $n=5$ for each time point) were i.p. treated with $100 \mathrm{mg} / \mathrm{kg} \mathrm{NCX} 4016$ and sacrificed $0.5,1,2,3,4 \mathrm{~h}$ post-administration. Two additional groups of animals $(n=5)$ were orally or i.p. treated with an equal volume of drug vehicle (pre-dose controls). Scheme I summarizes the experimental protocol.

\section{Blood, plasma and tissue preparation}

For blood and plasma sampling, the animals were anesthetized with intraperitoneal sodium pentobarbital $(60 \mathrm{mg} / \mathrm{kg})$ and venous blood withdrawn from abdominal vein by heparinized syringes. Venous blood was collected into tubes containing sodium heparinate $(5000 \mathrm{U} / \mathrm{ml})$ and EDTA (final concentration $30 \mu \mathrm{M}$ ), added with $\mathrm{NaF}(8 \mathrm{mg}$ per $\mathrm{ml})$ and centrifuged at $1500 \mathrm{~g}$ for $10 \mathrm{~min}$ at $4{ }^{\circ} \mathrm{C}$. The plasma samples were then transferred to $2 \mathrm{ml}$ cryovials and stored at $-80{ }^{\circ} \mathrm{C}$ until the analysis of $\mathrm{NOx}$ (chemiluminescence) and drug and metabolites (HPLC). Plasma aliquots from p.o./i.p. treated animals

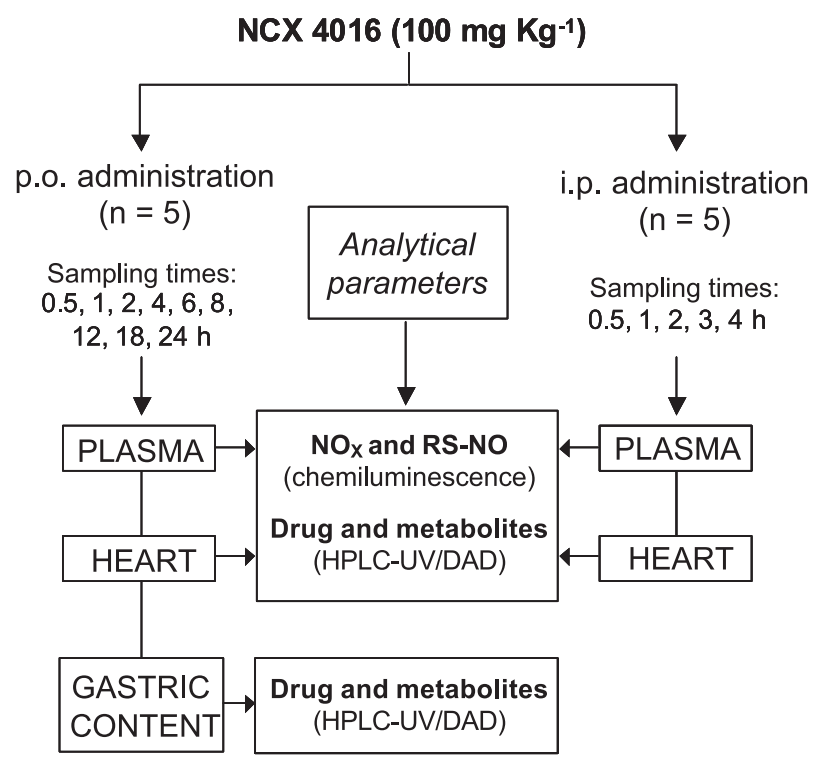

Scheme I. Experimental protocol: administration routes, markers and analytical methods. 
$(0.2 \mathrm{ml})$ were analyzed for conjugated metabolites following hydrolysis at $37{ }^{\circ} \mathrm{C}$ for $2 \mathrm{~h}$ with $\beta$ glucuronidase/arylsuphatase.

Blood samples used for measurement of endogenous RS-NO levels were collected into tubes containing EDTA (final concentration $2 \mathrm{mM}$ ) and NEM (final concentration $5 \mathrm{mM}$ ). All the samples were then centrifuged and stored as above described.

For tissue sampling, control and treated rats were killed by cervical dislocation; the hearts were excised and immediately perfused with cold $\mathrm{NaCl}(0.9 \%$, w/v), minced in cold $\mathrm{KCl}(1.15 \%$, w/v) and homogenized in $0.1 \mathrm{M}$ phosphate buffer, $\mathrm{pH} 7.4 \mathrm{using}$ an ultra-turrax T25 homogenizer (Janke and Kunkel, Ika). Heart homogenates $(0.1 \mathrm{~g}$ wet tissue $/ \mathrm{ml})$ were deproteinized with cold ethanol containing $10 \%$ perchloric acid ( $2 \mathrm{vol}$.), centrifuged at 20,000 rpm (5 min) and the supernatants, filtered through a $0.2 \mu \mathrm{m}$ filter, submitted to chemiluminescent and HPLC analyses ( $20 \mu 1$ aliquots). For chemiluminescent analysis of NOx, prior to determination the heart homogenate was washed with dichloromethane (3 volumes for 3 times) to eliminate drug and metabolites. The organic phases were discarded and the aqueous residue deproteinized and treated as above described. In orally treated animals the stomach was removed, opened and the gastric content recovered and extracted twice with $5 \mathrm{ml}$ acetonitrile. In parallel the gastric mucosa was thoroughly rinsed with the same solvent. The collected organic phases were evaporated to dryness under vacuum, taken up in $0.5 \mathrm{ml}$ mobile phase and submitted to HPLC analysis for drug and metabolites.

\section{Ozone-based chemilumiscent determination of plasma and tissue NOx and RS-NO}

NOx levels were determined on $0.25 \mathrm{ml}$ plasma aliquots deproteinized with cold ethanol $(1: 2 \mathrm{v} / \mathrm{v})$ and centrifuged at $14,000 \mathrm{rpm}$ (5 min) according to the method of Braman and Hendrix (1989) $\left(\mathrm{VCl}_{3}\right.$ reduction). The NOx content in plasma and tissues was determined on calibration curves prepared by adding known amounts of sodium nitrate to blank plasma or tissue homogenates in the concentration range $0.5-100 \mu \mathrm{M}$ and expressed as $\mu \mathrm{M}$ and nmoles/g wet tissue respectively. RS-NO were determined by a copper(I)/iodide/iodine-mediated cleavage of RS-NO to form NO (Marley et al., 2000), which was quantified by its chemiluminescent reaction in gas phase with ozone. The reaction chamber containing
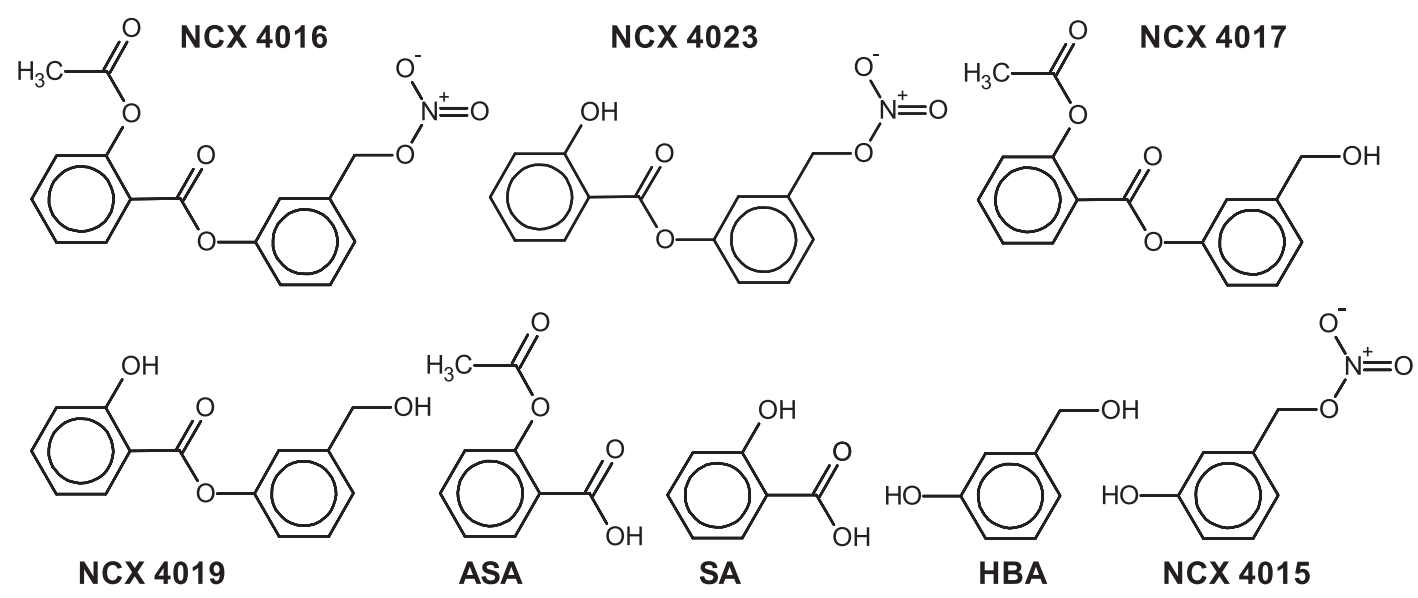

Fig. 1. Structures of NCX 4016 and of some postulated metabolic products. 
$4 \mathrm{ml}$ glacial acetic acid and $1 \mathrm{ml}$ potassium iodide $(50 \mathrm{mg} / \mathrm{ml})$ was kept at $70{ }^{\circ} \mathrm{C}$ via a water jacket. One minute prior to sample injection $(400 \mu \mathrm{l}$ plasma $+100 \mu \mathrm{l}$ of a $0.5 \%$ sulphanilamide solution in 0.1 $\mathrm{M} \mathrm{HCl}), 200 \mu \mathrm{l}$ of copper (II) sulphate $(200 \mathrm{mM})$ was added. This solution was constantly purged with helium and used only once per sample. The RS-NO content in plasma was determined on calibration curves prepared with GSNO (concentration range 0.05-5.0 $\mu \mathrm{M}$ ) and expressed as $\mu \mathrm{M}$. Data collection and analysis was performed using the NOAnalysis ${ }^{\mathrm{TM}}$ software (Sievers, Boulder, CO, USA).

\section{Statistical analysis}

All data are expressed as mean \pm S.D. $(n=5)$. For RS-NO and NOx parameters, the significance of differences among post-administration and pre-dose values was assessed by one way analysis of variance

a)

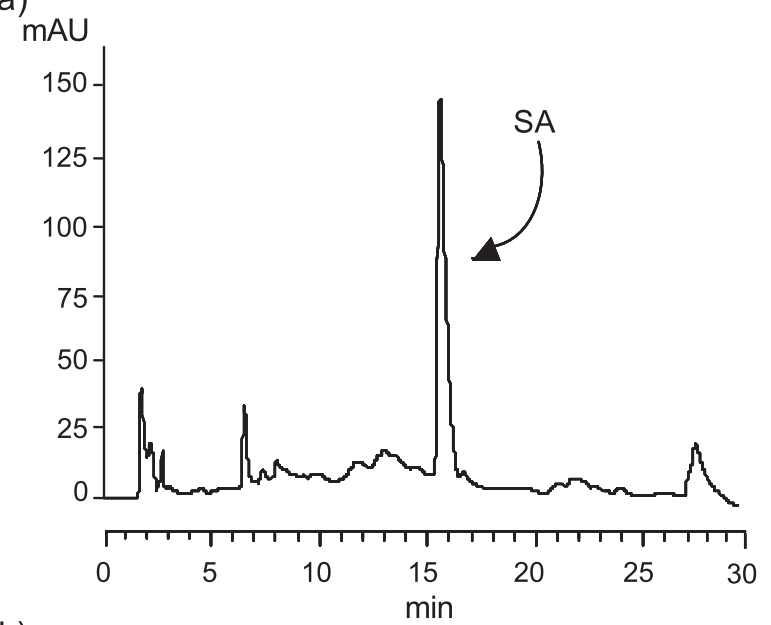

b)

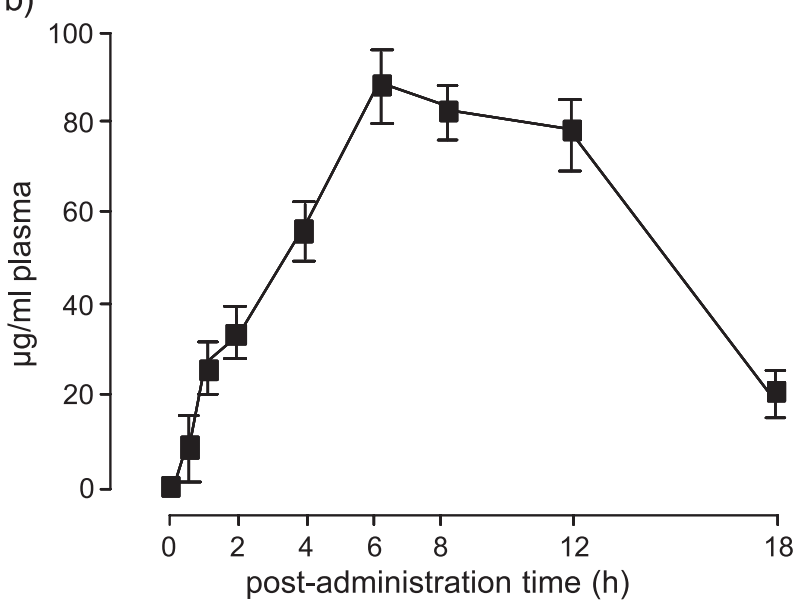

Fig. 2. HPLC analysis of plasma from rats p.o. treated with $100 \mathrm{mg} / \mathrm{kg} \mathrm{NCX} \mathrm{4016.} \mathrm{a)} \mathrm{Typical} \mathrm{chromatogram} \mathrm{of} \mathrm{a} \mathrm{plasma} \mathrm{sample}$ relative to $6 \mathrm{~h}$ post-administration. b) Time-course of SA formation in plasma. 
(ANOVA), followed by the Dunnett test (differences were considered significant when $\mathrm{p}<0.05$ ). Statistical analysis was performed by using the Prism software package (GraphPad Software Inc., San Diego, CA, USA).

\section{Results}

\section{Plasma levels of drug metabolites, NOx and nitrosothiols}

In previous studies (Carini et al., 2002) we have developed and validated a reverse-phase HPLC method able to efficiently separate NCX 4016 and its postulated metabolites arising from cleavage of different ester functions (Fig. 1) in biological matrices. The method has been applied in this study for

a)

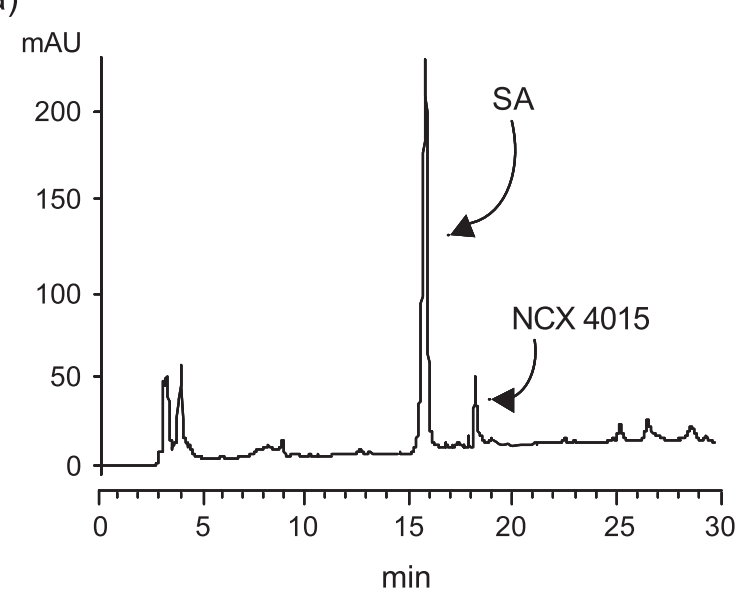

b)

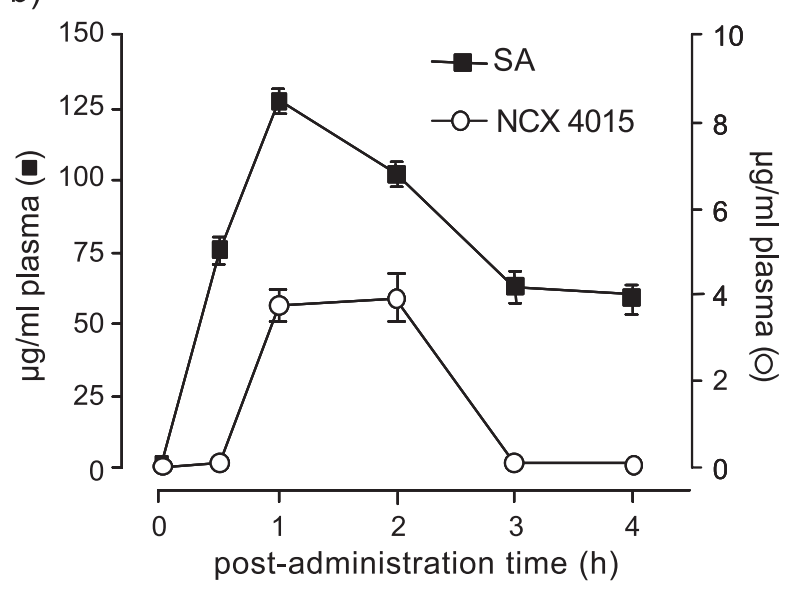

Fig. 3. HPLC analysis of plasma from rats i.p. treated with $100 \mathrm{mg} / \mathrm{kg}$ NCX 4016. a) Typical chromatogram of a plasma sample relative to $1 \mathrm{~h}$ post-administration. b) Time-course of SA and NCX 4015 formation in plasma. 
analysis of plasma and myocardial tissue samples from rats p.o. or i.p. treated with $100 \mathrm{mg} / \mathrm{kg} \mathrm{NCX}$ 4016. Fig. 2a shows a representative chromatographic profile of plasma from orally treated rats $(6 \mathrm{~h}$ postadministration). At all the observation times $(0.5-24 \mathrm{~h})$, no unchanged drug, nor the postulated metabolites were ever observed following oral administration and, as previously seen in rats chronically treated with $30 \mathrm{mg} / \mathrm{kg} \mathrm{NCX} 4016$ (Napoli et al., 2002), the only circulating metabolite was salicylic acid (SA), whose kinetics of formation, with a peak between $6-8 \mathrm{~h}(87.0 \pm 8.4$ and $82.6 \pm 7.8 \mu \mathrm{g} / \mathrm{ml})$, is reported in Fig. 2b.

No metabolic species were liberated following enzymatic hydrolysis of plasma samples. This excludes metabolites circulating in conjugated form.

Conversely, in i.p. treated animals (Fig. 3 a reports the chromatogram relative to $1 \mathrm{~h}$ post-dose), beside the main metabolite SA, whose formation is maximal at $1 \mathrm{~h}(C \max 127.7 \pm 6.9 \mu \mathrm{g} / \mathrm{ml}$ and plateau
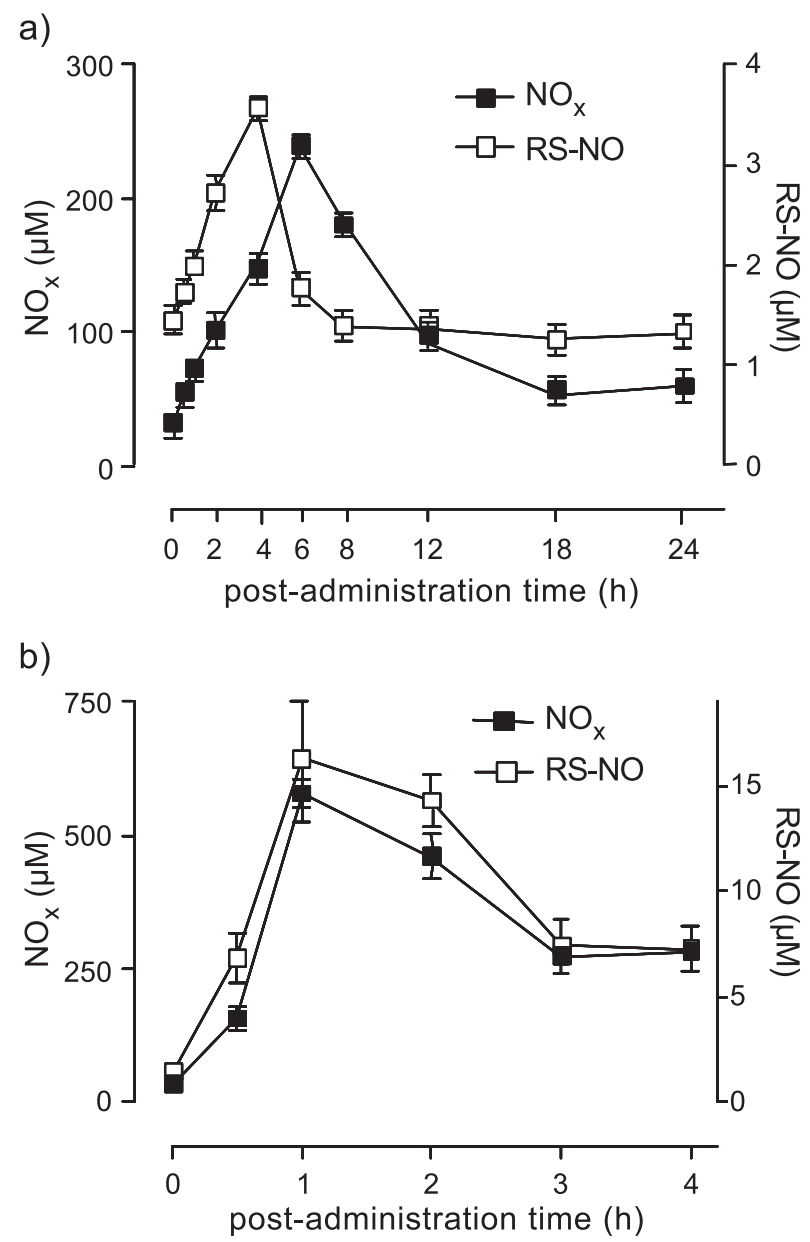

Fig. 4. Time-course of plasma NOx and S-nitrosothiols formation. a) p.o. treatment. NOx values were significant ( $p<0.05)$ vs. pre-dose values $(32.1 \pm 3.5 \mu \mathrm{M})$ in the $1-4 \mathrm{~h}$ interval. RS-NO values were significant $(\mathrm{p}<0.05)$ vs. pre-dose values $(1.45 \pm$ $0.29 \mu \mathrm{M})$ in the $1-12 \mathrm{~h}$ interval. b) i.p. treatment. All values were significant $(\mathrm{p}<0.05)$ vs. pre-dose values $(29.7 \pm 3.2 \mu \mathrm{M}$ for NOx and $1.28 \pm 0.31 \mu \mathrm{M}$ for RS-NO). 
between 1-2 h; Fig. 3b), the metabolite NCX 4015 (arising from cleavage in NCX 4016 of the benzoate ester) which participates to the delivery of the NO moiety, is also detectable at the first observation times, although at low concentration levels (Cmax $3.83 \pm 0.41 \mu \mathrm{g} / \mathrm{ml} 1 \mathrm{~h}$ post-dose) (Fig. 3b). No further NCX 4015 was released after enzymatic hydrolysis. The absence of NCX 4015 in orally treated animals and the very low plasma levels following i.p. administration indicate rapid conversion of this metabolite or tissue distribution/sequestration.

Then we determined by chemiluminescence analysis the plasma levels of NOx and RS-NO. Oral treatment (Fig. 4a) induced a time-dependent increase of NOx levels, more than a 7-fold increase at the 6th h compared with the pre-dose values $(238.7 \pm 7.2$ vs. $32.1 \pm 3.5 \mu \mathrm{M})$ and a parallel significant rise in S-nitrosothiols (peak at $4 \mathrm{~h}, 3.60 \pm 0.14$ vs. $1.45 \pm 0.29 \mu \mathrm{M}$ ). Following i.p. administration (Fig. 4b) the increase in both the parameters was earlier and significantly more pronounced: peak at $1 \mathrm{~h}(577.4 \pm$ $18.6 \mu \mathrm{M}$ for NOx; $16.3 \pm 2.9 \mu \mathrm{M}$ for RS-NO) and plateau between 1 and $2 \mathrm{~h}$. The kinetics of plasma RSNO formation following p.o. or i.p. treatment strictly parallels those of blood nitrosylhemoglobin, previously determined by ESR in the rat in the same experimental conditions (p.o. and i.p. administration of $100 \mathrm{mg} / \mathrm{kg}$ NCX 4016), where the maximal formation of the paramagnetic complex was observed at 4-

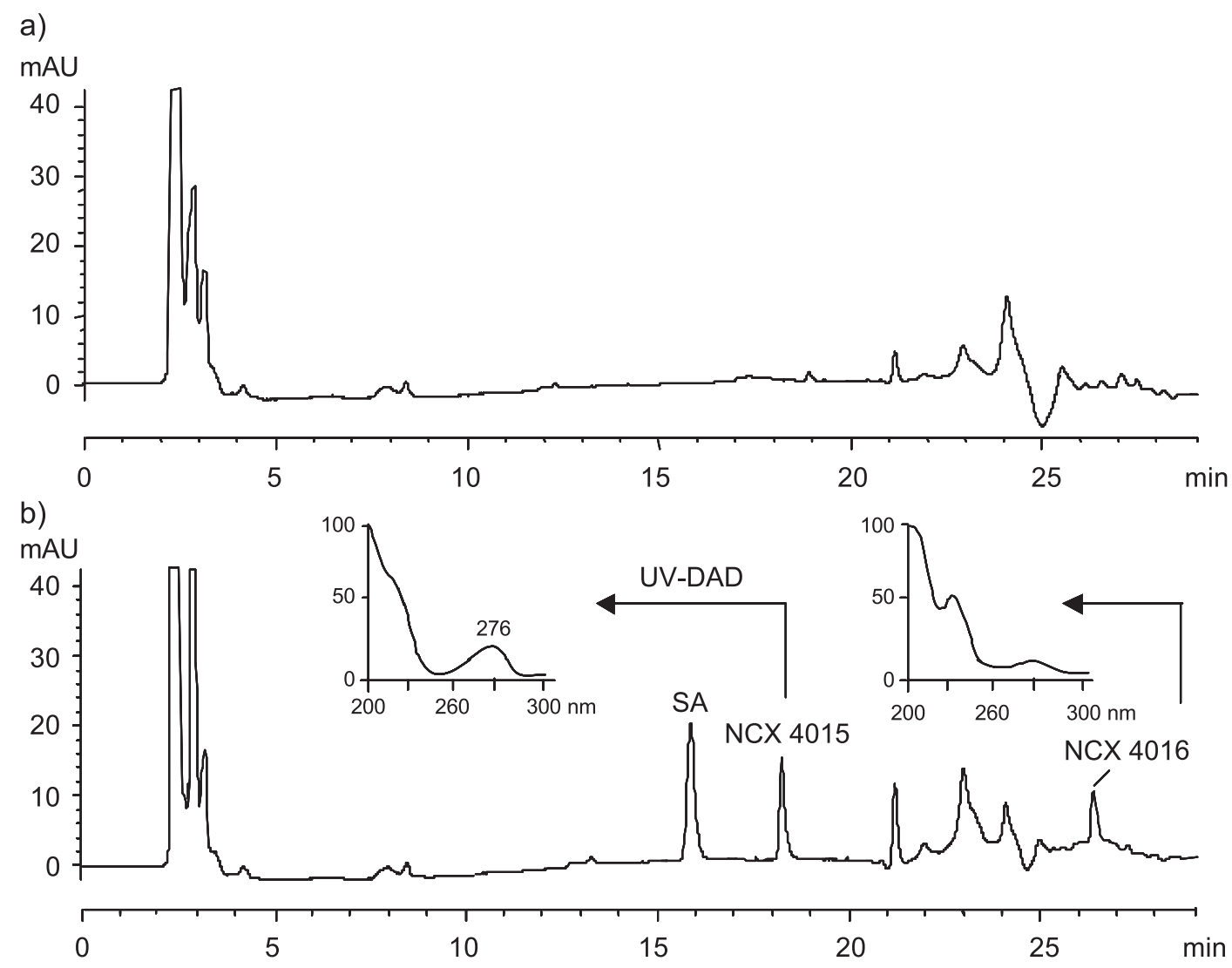

Fig. 5. Chromatographic profiles of myocardial samples from untreated (a) and i.p. treated animals $(100 \mathrm{mg} / \mathrm{kg} ; 1 \mathrm{~h}$ postadministration). Insert: UV-DAD spectra of peaks with R.T. 18.36 min (NCX 4015) and R.T. 26.46 min (NCX 4016). 
$6 \mathrm{~h}$ and $1-2 \mathrm{~h}$ respectively. This in accord with the theory that NO is exported from the erythrocytes to plasma thiol-containing molecules which readily deliver NO in the presence of transition metals (Pawloski et al., 2001; Gross, 2001).

\section{Myocardial levels of drug metabolites and NOx}

Since it has been recently demonstrated that chronically administered NCX 4016 (5 days; 10, 30 or $100 \mathrm{mg} / \mathrm{kg}$ ) displays a dose-dependent cardioprotection in rats subjected to myocardial ischemia/ reperfusion injury (reduction of the incidence of ventricular tachycardia and fibrillation and of infarct
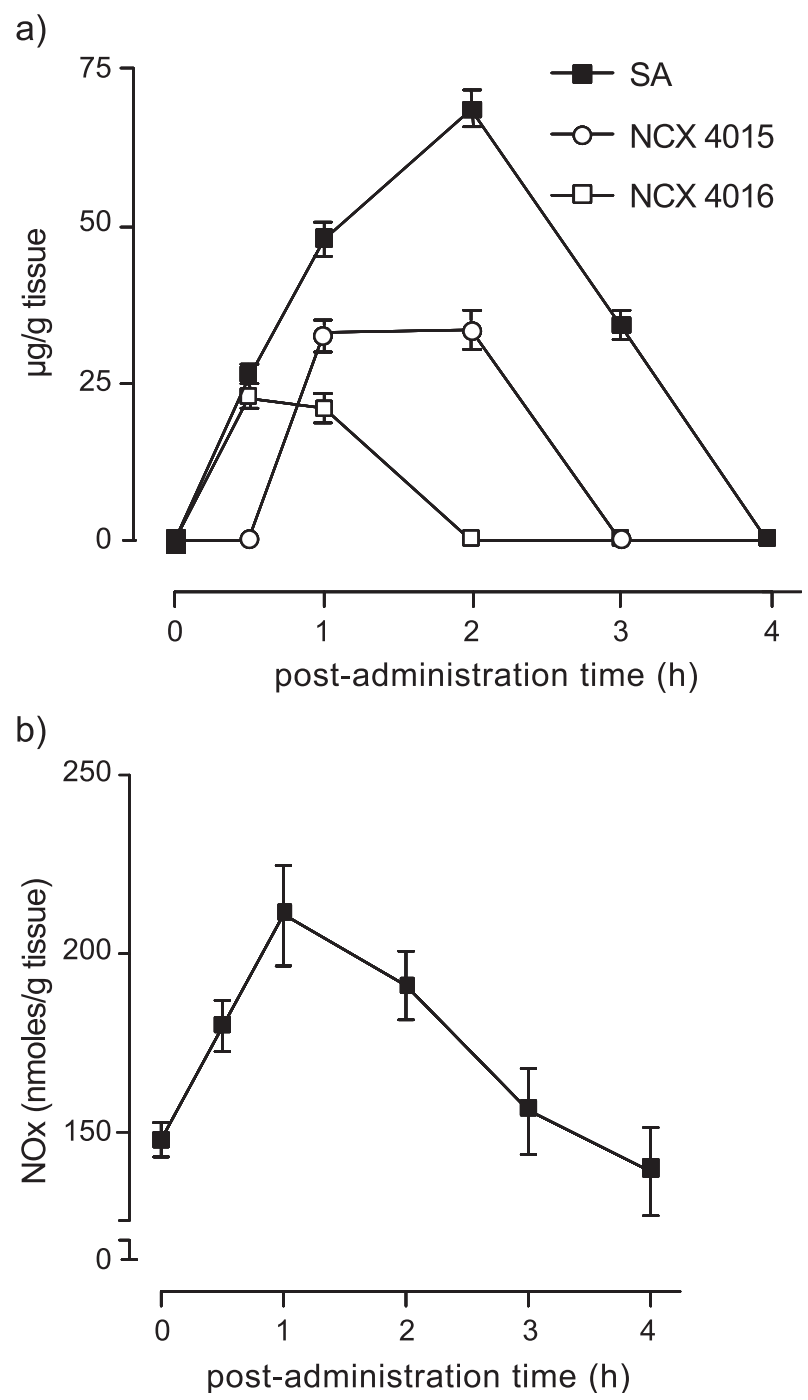

Fig. 6. Distribution of NCX 4016 and metabolites (a) and of NOx (b) in the heart of animals i.p. treated with $100 \mathrm{mg} / \mathrm{kg}$. NOx values were significantly different $(\mathrm{p}<0.05)$ from the pre-dose values $(147.5 \pm 9.7 \mathrm{nmoles} / \mathrm{g}$ tissue $)$ in the $0.5-2 \mathrm{~h}$ interval. 
size) (Rossoni et al., 2001), we have analysed the myocardial tissue from treated animals for the presence of the drug and metabolites and of NOx.

This was done to explore whether the effect could be ascribed to a specific compartmentalization of the drug/metabolites within the heart. No unchanged drug and metabolites were detectable at any observation time following a single oral dose, and NOx levels were always in the range of the controls (177.5 \pm 9.7 nmoles/g tissue; data not shown). Fig. 5b reports the LC-UV-DAD profile of a myocardial extract relative to $1 \mathrm{~h}$ post-dose after i.p. administration of NCX 4016, where besides SA (R.T. 15.6 min), two sharp peaks (absent in the controls) can be detected (R.T. 18.36 and 26.46 min). Both the compounds were identified, on the basis of their typical UV fingerprints (insert of Fig. 5b) as NCX 4015 and unchanged drug respectively. Thus, the analysis of myocardial samples at different post-administration times (Fig. 6a) indicates that, unlike to that observed following p.o. treatment, there is a rapid compartmentalization within the heart of the unchanged drug, which rapidly disappears $($ Cmax at $0.5 \mathrm{~h}=$ $22.6 \pm 2.4 \mu \mathrm{g} / \mathrm{g}$ tissue) in favour of its breakdown products (Cmax SA $68.4 \pm 2.9 \mu \mathrm{g} / \mathrm{g}$ tissue at $2 \mathrm{~h}$; Cmax NCX $401533.5 \pm 3.2 \mu \mathrm{g} / \mathrm{g}$ tissue).
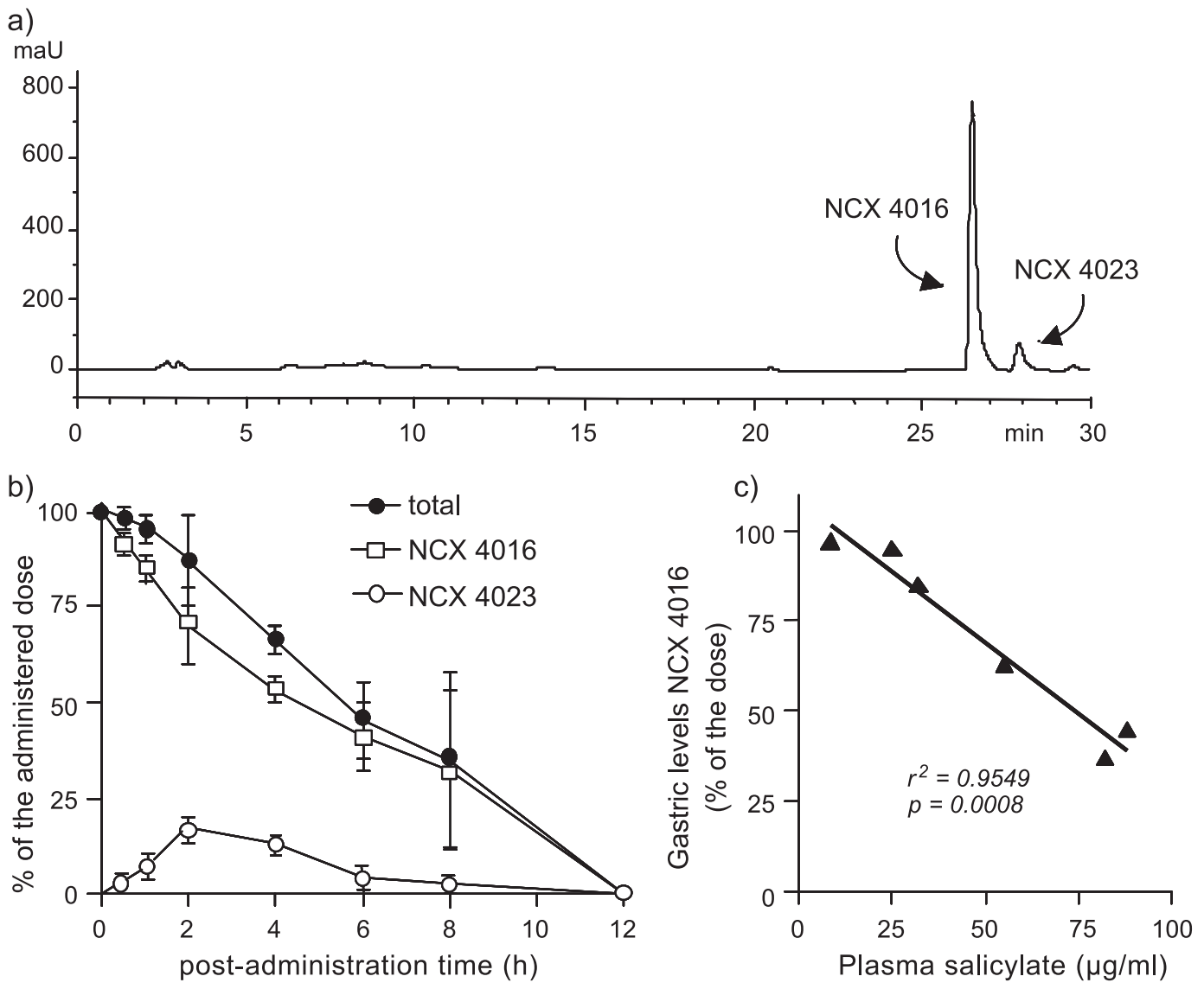

Fig. 7. HPLC analysis of gastric content from rats p.o. treated with $100 \mathrm{mg} / \mathrm{kg}$ NCX 4016. a) Chromatographic profile of a sample relative to $6 \mathrm{~h}$ post-administration. b) Time-dependent decline of gastric NCX 4016 and formation of NCX 4023 (deacetylated metabolite). c) Correlation between plasma levels of SA and residual gastric levels of NCX $4016+$ NCX 4023 . 
NCX 4016 distribution within the heart is paralleled by a rise in myocardial NOx levels (Fig. 6b) from $147.5 \pm 9.7 \mathrm{nmoles} / \mathrm{g}$ tissue (pre-dose value) to $210.4 \pm 14.1 \mathrm{nmoles} / \mathrm{g}$ tissue $(\mathrm{p}<0.05)$ at $1 \mathrm{~h}$ postdose and to $190.8 \pm 9.3 \mathrm{nmoles} / \mathrm{g}$ tissue at the $2 \mathrm{~h}$ time point, followed by a decline to $138.7 \pm 12.0$ nmoles/g tissue at the last observation time.

\section{Analysis of gastric content}

To check the stability of NCX 4016 in the acidic gastric milieu, to explain the different behaviour/ distribution of the drug following p.o. or i.p. administration and for a better understanding of the role of the gastrointestinal tract in the absorption of the drug, we have examined the gastric content of the orally treated animals at different post-dosing times by HPLC. The unchanged drug (high levels) and its deacetylated metabolite NCX 4023 (low levels) were detected at all the observation times, but no one of the other postulated metabolites (Fig. 7a reports the chromatogram of the extract relative to $6 \mathrm{~h}$ postadministration). This, and especially the absence of de-nitrated metabolites NCX 4017 and NCX 4019, indicates a high stability of the drug and of the nitrate ester function in the gastric environment, and indirectly excludes a local release of NO. The time-dependent decline of NCX 4016 and formation of NCX 4023 in the gastric content (both quantitated by HPLC analysis) is reported in Fig. 7b: the results indicate a slow absorption process of the drug, since $2 \mathrm{~h}$ post-administration, the residual gastric amount (calculated as sum of the unchanged drug and its de-acetylated metabolite) accounts for more than $80 \%$ of the administered dose, and high levels of NCX 4016 are still detectable at the 8th $\mathrm{h}$ post-dose (approximately $30 \%$ of the dose). The kinetics of NCX 4016 disappearance from the stomach is inversely related to that of plasma formation of the main metabolite SA: the slow release of NCX 4016 from the stomach is confirmed by the highly significant negative correlation between residual gastric amounts of the drug and plasma salicylate levels (Fig. $7 \mathrm{c}, \mathrm{r}^{2}=0.9549 ; \mathrm{p}=0.0008$ ).

\section{Discussion}

The results of this study provide clear evidence that NCX 4016 is able to slowly, but progressively release the vasodilating moiety, NO, after oral administration in the rat. Some of this $\mathrm{NO}$ is metabolically converted to the oxidation products, $\mathrm{NO}_{2}^{-}$and $\mathrm{NO}_{3}^{-}$. Another proportion of the $\mathrm{NO}$ is stored as nitrosylhemoglobin $\mathrm{HbFe}(\mathrm{II}) \mathrm{NO}$ and S-nitrosothiols. The perfect match, for the entire time period (1$24 \mathrm{~h}$ ), between the plasma peak of salicylic acid and that of the final oxidized metabolites of NO (NOx) suggests a slow absorption/distribution process of the molecule, with a peak of NO delivery between 4 and $6 \mathrm{~h}$. The results relative to i.p. administration $(100 \mathrm{mg} / \mathrm{kg})$ show a more pronounced and rapid NO delivery, still coincident with the plasma peak of SA, and small but well detectable NCX 4015 levels. One of the findings of major relevance of our work is the demonstration that after acute i.p. administration, NCX 4016 and its active metabolite NCX 4015 are able to reach the heart. Concomitant to their presence, we observe in myocardial tissue an increase of the NOx levels, which, although considered indirect marker for NO, are a clear indication of its formation. Very likely, due to the high concentration of NCX 4016 following i.p. administration, part of this is able to escape to the hematic/ hepatic hydrolytic breakdown and localize within the myocardial tissue, the drug intake being favoured by its lipophilic character $(\log \mathrm{P}=2.89$ ), reflecting the passage through the sarcolemma (Horowitz and Powell, 1986). 
To our knowledge, this is the first demonstration (using a fully validated technique) of an increase of NOx levels in this tissue following administration of a NO-donor drug. In our case the increase in NO levels in the heart is further corroborated by the previous experiments where, using the more specific and unequivocal technique, ESR, we have observed a clear cut increase in the signal relative to the nitrosylmyoglobin paramagnetic complex (Carini et al., 2001) after i.p. treatment of rats with the same dosage of drug.

The strictly parallel relationship between concentrations of unchanged drug, the NCX 4015 metabolite and increases in NOx could indicate that the delivery of NO to myocardial tissue, after i.p. administration, is mediated, in addition to bioactive storage forms of $\mathrm{NO}$, by nitrate ester species which may undergo a denitration process in situ.

After p.o. treatment the levels of unchanged drug and metabolites in myocardial tissue are below the limit of detection, and NOx levels were not statistically different from the pre-dose values. This means that cardioprotection (Rossoni et al., 2001) with chronically administered NCX 4016 is predominantly mediated by an increase of circulating bioactive storage forms (nitrosylhemoglobin and plasma RS-NO), which have been shown to triplicate after oral chronic treatment (Napoli et al., 2002).

The second major finding is the demonstration (although indirect) that no de-nitration occurs in the upper gastrointestinal tract following oral administration. The experiments performed on the release of NCX 4016 from the stomach are evidence that the drug is stable in the gastric acidic milieu (no denitrated metabolites and small amounts of the O-deacetylated derivative NCX 4023 were detected up to 8 hours post-dosage), where it persists basically in unchanged form until $12 \mathrm{~h}$, with a slow and progressive decline which strictly parallels the appearance in plasma of salicylic acid. The same behaviour was observed in previous and preliminary studies on gastric content from rats treated with a single lower oral dose $(50 \mathrm{mg} / \mathrm{kg}$ ) (Carini et al., 2000). These results are in contrast with those of Takeuchi et al. (1998) which found significantly elevated NOx levels in gastric juice after intragastric administration of NCX $4016(33 \mathrm{mg} / \mathrm{kg})$ in pylorus-ligated rats. However, since the Authors are dealing with non-physiological conditions (they do not specify to which extent pylorus ligation might affect

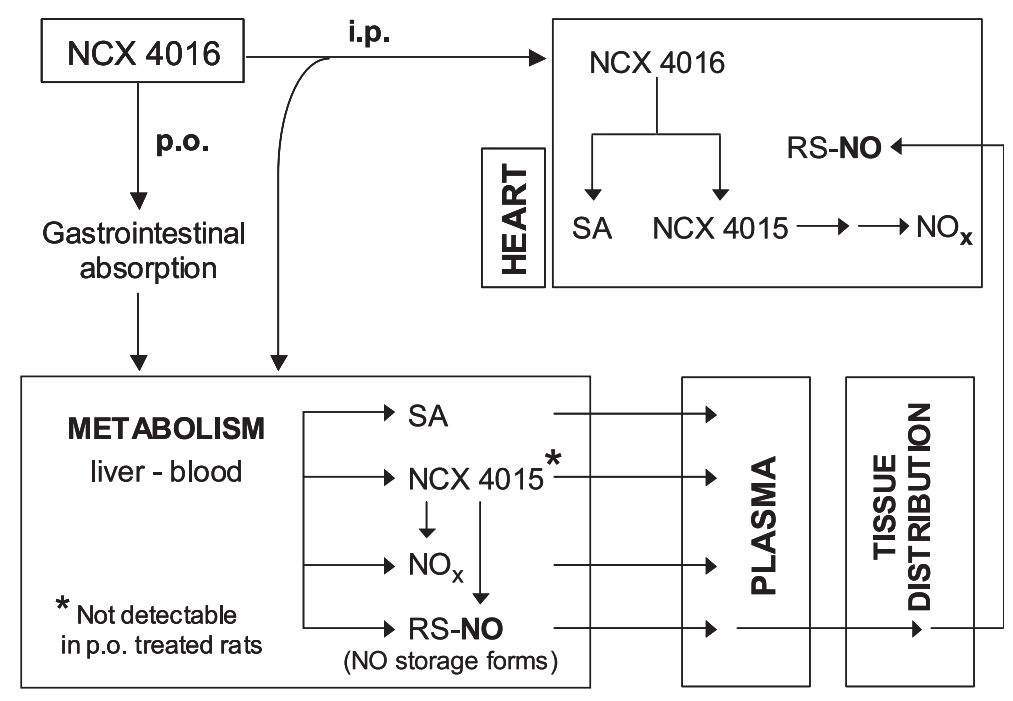

Scheme II. Postulated metabolic disposition of NCX 4016 following oral and i.p. administration. 
local gastric $\mathrm{pH}$ ), and they used for NOx determination the Griess method, universally considered as poorly reliable, we are considering this increase as artifactual or not physiological. Further studies are in progress to estimate the gastric levels of NOx and RS-NO following oral administration by the more sensitive, specific and unequivocal chemiluminescent assay.

Hence, we hypothesize that the drug reaches the intestine in the unchanged form, and the part that escapes the attack of the hydrolytic enzymes of intestinal microflora (extra-hepatic metabolism) is absorbed as such, enters the liver where, as previously demonstrated (Carini et al., 2002), it undergoes rapid conversion to SA and NCX 4015. Scheme II summarizes the metabolic disposition of the drug.

\section{Conclusions}

In conclusion, the results of this study demonstrate that the NO-dependent gastroprotective effect of NCX 4016 is not due to a luminal NO release and subsequent diffusion through the gastric mucosa, but to a systemic metabolism of NCX 4016 and consequent NO release which, through the bioactive storage forms, is delivered at gastric level. The slow release process from the stomach followed by an extensive hepatic first pass is further confirmed by the fact that in plasma we have never found the unchanged drug, nor its O-deacetylated metabolite (NCX 4023), NCX 4015 or its de-nitrated product HBA, nor HBAC. The key role of gastrointestinal tract in drug absorption and NO delivery is further substantiated by our previous studies (Carini et al., 2001) where significantly different peak levels of nitrosylhemoglobin (the unequivocal blood marker of NO release) were determined after p.o. and i.p. administration of $100 \mathrm{mg} / \mathrm{kg} \mathrm{NCX} 4016$ in the rat $(0.68 \pm 0.14 \mu \mathrm{M}$ vs. $5.5 \pm 1.2 \mu \mathrm{M})$. All these data explain why oral administered NCX 4016 does not give rise, in vivo, to the typical adverse effects of conventional NOdonors since the stomach acts as a reservoir for the drug, causing it to release NO slowly.

\section{Acknowledgements}

Financial support from MURST (Cofinanziamento Programma Nazionale 2002) is gratefully acknowledged. We thank NicOx, S.A. (Sophia Antipolis, France) for the provision of NCX 4016 and metabolites.

\section{References}

Alencar, J.L., Lobysheva, I., Geffard, M., Sarr, M., Schott, C., Schini-Kerth, V.B., Nepveu, F., Stoclet, J.C., Muller, B., 2003. Role of S-nitrosation of cysteine residues in long-lasting inhibitory effect of nitric oxide on arterial tone. Molecular Pharmacology 63 (5), 1148-1158.

Bak, A.W., Mc Knight, W., Li, P., Del Soldato, P., Calignano, A., Cirino, G., Wallace, J.L., 1998. Cyclooxygenaseindependent chemoprevention with an aspirin derivative in a rat model of colonic adenocarcinoma. Life Sciences 62 (23), PL367-PL373.

Braman, R.S., Hendrix, S.A., 1989. Nanogram nitrite determination in environmental and biological materials by vanadium (III) reduction with chemiluminescence detection. Analytical Chemistry 61 (24), 2715-2718.

Carini, M., Aldini, G., Orioli, M., Maffei Facino, R., 2002. In vitro metabolism of a nitroderivative of acetylsalicylic acid (NCX 4016) by rat liver: LC and LC-MS studies. Journal of Pharmaceutical and Biomedical Analysis 29 (6), $1061-1071$.

Carini, M., Aldini, G., Stefani, R., Maffei Facino, R., Rossoni, G., Del Soldato, P., 2000. Detection and quantitation of nitrosyl- 
hemoglobin and nitrosothiols in rat blood and plasma after a single oral dose of nitroaspirin. In: Velo, G., Perucca, E. (Eds.), Joint Meeting of VII World Conference on Clinical Pharmacology and Therapeutics IUPHAR - Division of Clinical Pharmacology and 4th Congress of the European Association for Clinical Pharmacology and Therapeutics (EACPT), Florence, Italy, June 15-20. Blackwell Science, Oxford.

Carini, M., Aldini, G., Stefani, R., Orioli, M., Maffei Facino, R., 2001. Nitrosylhemoglobin, an unequivocal index of nitric oxide release from nitroaspirin: in vitro and in vivo studies in the rat by ESR spectroscopy. Journal of Pharmaceutical and Biomedical Analysis 26 (4), 509-518.

Del Soldato, P., Sorrentino, R., Pinto, A., 1999. NO-aspirins, a class of new anti-inflammatory and anti-thrombotic agents. Trends in Pharmacological Sciences 20 (8), 319-323.

Gladwin, M.T., Lancaster, J.R., Freeman, B.A., Schechter, A.N., 2003. Nitric oxide's reactions with hemoglobin: a view through the SNO-storm. Nature Medicine 9 (5), 496-500.

Gow, A.J., Luchsinger, B.P., Pawloski, J., Singel, D.J., Stamler, J.S., 1999. The oxyhemoglobin reaction of nitric oxide. Proceedings of the National Academy of Science USA 96 (16), 9027-9032.

Gross, S.S., 2001. Targeted delivery of nitric oxide. Nature 409 (6820), 577-578.

Horowitz, J.D., Powell, A.C., 1986. Myocardial uptake of drugs and clinical effects. Clinical Pharmacokinetics 11 (5), $354-371$.

Marley, R., Feelish, M., Holt, S., Moore, K., 2000. A Chemiluminescense-based assay for S-nitrosoalbumin and other plasma S-nitrosothiols. Free Radical Research 32 (1), 1-9.

Miller, M.R., Hanspal, I.S., Hadoke, P.W., Newby, D.E., Rossi, A.G., Webb, D.J., Megson, I.L., 2003. A novel S-nitrosothiol causes prolonged and selective inhibition of platelet adhesion at sites of vascular injury. Cardiovascular Research 57 (3), $853-860$.

Napoli, C., Aldini, G., Wallace, J.L., De Nigris, F., Maffei Facino, R., Abete, P., Bonaduce, D., Condorelli, G., Rengo, F., Sica, V., D’Armiento, F.P., Mignognia, C., Rosa, G., Condorelli, M., Lerman, L.O., Ignarro, L.J., 2002. Efficacy and age-related effects of nitric oxide-releasing aspirin on experimental restenosis. Proceedings of the National Academy of Science USA 99 (3), 1689-1694.

Napoli, C., Aldini, G., Fallace, J.L., De Nigris, F., Maffei Facino, R., Abete, P., Bonaduce, D., Condorelli, G., Ignarro, L.J., 2002. Age-related effects of nitric oxide-releasing aspirin on release of bioactive nitric oxide and restenosis after balloon injury. Proceedings of the National Academy of Science USA 99 (3), 1689-1694.

Napoli, C., Ignarro, L.J., 2003. Nitric oxide-releasing drugs. Annual Review of Pharmacology and Toxicology 43, 97-123.

Pawloski, J.R., Hess, D.T., Stamler, J.S., 2001. Export by red blood cells of nitric oxide bioactivity. Nature 409 (6820), $622-626$.

Rassaf, T., Kleinbongard, P., Preik, M., Dejam, A., Gharini, P., Lauer, T., Erckenbrecht, J., Duschin, A., Schulz, R., Heusch, G., Feelisch, M., Kelm, M., 2002. Plasma nitrosothiols contribute to the systemic vasodilator effects of intravenously applied NO: experimental and clinical study on the fate of NO in human blood. Circulation Research 91 (6), $470-477$.

Rigas, B., Kalofonos, H., Lebovics, E., Vagenakis, A.G., 2003. NO-NSAIDs and cancer: promising novel agents. Digestive and Liver Disease 35 (Supplement 2), S27-S34.

Rigas, B., Williams, J.L., 2002. NO-releasing NSAIDs and colon cancer chemoprevention: a promising novel approach. International Journal of Oncology. 20 (5), 885-890.

Rossoni, G., Manfredi, B., Colonna, V.D., Bernareggi, M., Berti, F., 2001. The nitroderivative of aspirin, NCX 4016, reduces infarct size caused by myocardial ischemia-reperfusion in the anesthetized rat. Journal of Pharmacology and Experimental Therapeutics 297 (1), 380-387.

Takeuchi, K., Ukawa, A., Konaka, A., Kitamura, M., Sugawa, Y., 1998. Effect of nitric oxide-releasing aspirin derivative on gastric functional and ulcerogenic responses in rats: comparison with plain aspirin. The Journal of Pharmacology and Experimental Therapeutics 286 (1), 115-121.

Wallace, J.L., Ignarro, L.J., Fiorucci, S., 2002. Potential cardioprotective actions of NO-releasing aspirin. Nature Reviews Drug Discovery 1 (5), 375-382. 